\title{
Research on Interactive Development of Urban and Rural Teachers in Chengdu
}

\author{
Lu Huang \\ School of Political Science and Public Administration \\ University of Electronic Science and Technology of China \\ Chengdu, China 610000
}

\author{
Xi Yang \\ School of Political Science and Public Administration \\ University of Electronic Science and Technology of China \\ Chengdu, China 610000
}

\begin{abstract}
Under the background of full implementation of the strategy of balancing urban and rural development by our party and country, the balanced development of education has become an inevitable choice for education reform and development. However, as an important resource and factor of education, teacher has played a decisive role in promoting the integration of urban and rural education. Through sorting out the practice and exploration of the interactive development of urban and rural teachers in Chengdu, the achievements and deficiencies can be summarized. We can apply public products theory, public choice theory and theory of equalization of public services, and deeply analyze the existing problems and put forward innovative suggestions. It plays a positive role in enriching the related theories of the interactive development of urban and rural teachers and promoting the orderly implementation of the strategy of balancing urban and rural development in Chengdu.
\end{abstract}

Keywords—urban and rural; teacher; interactive development

\section{INTRODUCTION}

Under the perspective of "three circles in one" of Chengdu city, the interactive development of urban and rural teachers in Chengdu takes regional educational alliance as the framework and takes cross regional school twining as its carrier, gives full play to the educational advantages and characteristics of the cities and districts of the three spheres, promotes the flow of teacher resources in the circles and urban and rural areas, and realize the common promotion of urban and rural teachers. ${ }^{1}$ The aim is to narrow the gap of teachers' level in urban and rural areas, to promote the integration and balance of the whole Chengdu education and to promote the balance development of urban and rural education in a larger scale and a higher level.

\section{THEORETICAL BASIS}

\section{A. Public Products Theory}

According to the theory of public economics, social products can be divided into public products and private products. Education belongs to quasi public products, with no excludability but competitiveness. According to the attributes and characteristics of educational products, the multiple supply

Chengdu Regional Education Alliance Development Report Compilation Group. Report on the Development of Chengdu Regional Education League[M]. Beijing: People's Publishing House, 2015: 3-45. system of education should be arranged, so as to balance the demand and supply of education. ${ }^{2}$ Due to the inequality of quality, quantity, structure and other aspects of teachers in urban and rural areas, it leads students to choose schools and choose a school with higher teacher' level, which undoubtedly drive students to flock to urban quality schools. Therefore, from the theory of public products, we can solve the supply of teachers in rural weak schools.

\section{B. Public Choice Theory}

The theory of public choice is a kind of new cross subject between economics and politics. It is the theory that applies the economic analysis to study how the political decision-making mechanism works. ${ }^{3}$ Interactive development of urban and rural teachers involves many interest entities, including government, school, teachers and even students and their parents. Therefore, it is necessary to apply the theory of public choice, assuming multi interest entities as rational economic men, using costbenefit analysis to explain the relationship between individual preference and government public choice, to ensure that government can make education policies and offer education products in accordance with the will of the majority of interest entities.

\section{Theory of Equalization of Public Services}

The equalization of public services is the basic target of public finance, refers to that government should provide the public with basic public goods and public services which has different standards at different stages and is ultimately rough equal. The equalization of public services contributes to fair distribution and the unification of fairness and efficiency. At present, the gap between regions, urban and rural areas and different groups of China's educational service has gradually widened, which has become one of the focuses of social equity and justice. ${ }^{5}$ The implementation of equalization of public

2 Liu Wei, Zhu Chengke. The Plight and Countermeasures of the Implementation of Teacher's Rotation System in Rural Areas[J]. Teaching and Administration, 2010, (22):6-8

${ }^{3}$ Fang Fuqian. The Modern West Public Selection and Its Three Schools[J]. Teaching and Research, 1997, (10): 29-34+63.

${ }^{4}$ Song Yanqing, Wang Xuanhua. Literature Review of Public Choice Theory[J]. Commercial Times, 2009, (35):14-16.

${ }^{5}$ Chen Shuquan. A Study of the Policy Approach on Equalization of Compulsory Education Public Services: Taking Shandong Province for Example[J]. Shandong Social Sciences, 2011, (05):170-173. 
service is of great significance to the balanced development of education.

\section{OVERALL DESIGN OF INTERACTIVE DEVELOPMENT OF URBAN AND RURAL TEACHERS IN CHENGDU}

\section{A. Guiding Ideology}

We should adhere to take the principle of promoting fairness and justice and promoting the well-being of the people as starting point and foothold, and take the realization of allocation of teacher resources in primary and secondary schools in the whole area of Chengdu as goals. Under the premise of strictly controlling utilities staffing quota, we should promote the proper redistribution of urban and rural teacher resource and drive the balanced development and scientific development of Chengdu's education.

\section{B. Practice Principle}

1) Principle of equality and complementation

Both urban and rural areas should fully understand the development demands of each other's teachers, and jointly plan and formulate development goals to promote mutual complementation, mutual improvement and achieve common development.

\section{2) Principle of interaction and sharing}

Both urban and rural areas should carry out activities combining regular and irregular time. We should share highquality educational resources, characteristic education bases and practice bases, and strengthen cooperation in major projects to achieve all-around integration and development.

\section{3) Characteristic development principle}

We should fully respect the cultural differences of counties and schools, and pay attention to training and developing different cultural characteristics of teachers, while improving the overall teacher's level and creating distinctive team culture of teachers.

\section{Policy Development Process}

In 2012, the Opinions on Further Deepening the Allocation of Public Education Resources in Counties and Cities mentioned in the report that deepening the balanced allocation of teacher resources is one of the important tasks. We should improve the teacher management mechanism, the teacher allocation mechanism of "county administration and school applying", and the teacher exchange system and the principle exchange system of compulsory educational school. In the same year, the Opinions on Promoting Teacher's "County Administration and School Applying” Work mentioned that we should enhance the intensity of teacher's interaction and implement "county administrates the coordination work and school picks over the high quality teachers".

In 2014, the Implementation Opinions on Strengthening the Construction of Teaching Body mentioned that we should promote the reform of management system of teachers, including the improvement of teacher exchange mechanism of "city planning as a whole". The same year, the Guidance Suggestions on Further Optimizing and Allocating the Teacher
Resources of the Whole City's Primary and Secondary School mentioned that we should explore a new mode of comprehensive deployment of high-quality teachers, requiring teachers to conduct the regular flow and comprehensive deployment, and constantly expand the coverage and radiation driving range of high-quality educational resources.

In 2015, the Opinions on Deepening the Development of Regional Education Alliance proposed that we should strictly enforce the two-way exchange system for personnel and deepen the cross-regional exchanges and interactions of cadre teachers.

In 2016, the Key Points of Chengdu Teachers' Personnel Work in 2016 pointed out that we should strengthen the construction of educational talents and optimize the interaction work of teachers in compulsory education,

In 2017, the Key Points of Chengdu Teachers' Personnel Work in 2017 pointed out that we should focus on the work of rural teachers, promote the balanced allocation of teachers and carry out a good job of interaction and supporting education work of cadre teachers.

\section{Urban and Rural Teacher's Interaction Initiatives in Chengdu}

Relying on alliance framework of regional education and combining with exchanges and cooperation between schools, we should gradually establish and improve the cross regional flow system of cadre teachers, so as to promote the training and cultivating of urban and rural teachers.

\section{1) Interaction between urban and rural cadres}

a) Strengthen the exchange of school management in urban and rural areas.

First, urban and rural education bureaus should adopt the measures of long-term station, when the communication time is above one school year, and then sends young cadres to counterparts to take a temporary post. Second, urban and rural schools should take interactive ways of combing short term, medium term with long term.

\section{b) Devote to build an efficient management team.}

First, the headmasters of urban and rural schools study and exchange management experience and explore new ideas and ways of management through training, forums and salons. Second, they can take the theme of educational practice activities as the carrier, and constantly improve the business level of urban and rural management team.

c) Learn and share the educational management results of urban and rural areas.

Schools in urban and rural areas adopt different forms to further study the management results of education and teaching, moral education and construction of campus culture in counterparts. 
2) Teachers' interactive activities in urban and rural areas

a) Cadre teachers demonstrate and lead other teachers.

Schools in urban and rural areas should give full play to the demonstration and leading role of cadre teachers, build a studio for famous teachers, and promote the overall optimization of urban and rural teaching bodies. Schools in urban and rural areas should pass the advanced education ideas of cadre teachers to the other side through the demonstration class, the observation class, the review class, the examination proposition, the collective lesson preparation and other forms in each semester. Cadre teachers in urban and rural areas should be invited to guide the practical teaching in other's school, participate in some activities such as teaching and research before competition, taking lessons in competition and evaluation after competition and impact teaching experience to others without reservation.

\section{b) Study for the post.}

Teachers in urban and rural areas should go to each other's school to study for the post and have a full communication with school teachers through attending lectures, listening to expert's reports and inspecting and competing in course and other forms. But it needs to pay attention to that we should choose the right time and right people of the post, and study for the post in many ways.

\section{c) Master-apprentice connection.}

Teachers in urban and rural areas should carry out the activities of master-apprentice connection, develop the "one to one" targeted guidance and practically help teachers in urban and rural areas to grow rapidly.

\section{Situation ANAlysis OF INTERACTIVE DEVELOPMENT OF URBAN AND RURAL TEACHERS IN CHENGDU}

\section{A. Efficiency of Interactive Development of Urban and Rural Teachers in Chengdu}

In the 2015-2016 academic years, the total exchanged number of cadre teachers in urban and rural areas was 1553, which accounted for $0.77 \%$ of the total number of cadre teachers in the city. Among them, the exchanged number of cadres was 667 , and the communication time in half one year was 201, more than half one year to less than one year was 166 , more than one year to two years was 35 , more than two years to three years was 109 and the number above three years was 13 ; the total exchanged number of teachers was 886 , and the communication time in half one year was 310 , more than half one year to less than one year was 252 , more than one year to two years was 17 , more than two years to three years was 15 and the number above three years was 5 .

\section{B. Problems of Interactive Development of Urban ad Rural Teachers in Chengdu}

1) The interaction process development of urban and rural teachers is not sound.

The process development of interactive development of urban and rural teachers in Chengdu should include the four aspects, such as teacher selection, task setting, tracking supervision, appraisal, rewards and punishments. At present, the relevant documents only refer to the part of teacher selection and evaluation. The documents mention that the categories of selection should be divided into cadre exchange and teacher exchange, and the number of selection people should be appointed. The documents also stipulate that the condition of exchanged teachers should be teaching more than three years, male less than 50 years old and women less than 45 years old. From the perspective of selection condition of teachers, if we have been teaching for three years but do not have experience the complete teaching stage at the elementary school. These teachers have no rich experience in their school and it will be difficult for them to adapt the educational environment when they participate in the interactive communication. Although documents have mentioned the tendency to assessment and evaluation, it is a kind of incentive means and the results are not defined by rewards and punishments. Generally speaking, the current process lacks task setting and tracking supervision, and the interactive teachers will be passive, lazy and fool around. "Table I"

TABLE I. Statistical TABle of InTERACTIVE COMMUNiCATION OF URBAN AND RURAL TEACHERS

\begin{tabular}{|c|c|c|c|c|c|c|}
\hline$\overbrace{\text { Category }}^{\text {Time }}$ & $\begin{array}{c}\text { Total } \\
\text { number }\end{array}$ & $\begin{array}{l}\text { Half one year } \\
\text { (number of } \\
\text { people) }\end{array}$ & $\begin{array}{l}\text { More than half one year to } \\
\text { less than one year (number } \\
\text { of people) }\end{array}$ & $\begin{array}{c}\text { More than one } \\
\text { year to two years } \\
\text { (number of people) }\end{array}$ & $\begin{array}{c}\text { More than two years } \\
\text { to three years } \\
\text { (number of people) }\end{array}$ & $\begin{array}{c}\text { Above three years } \\
\text { (number of } \\
\text { people) }\end{array}$ \\
\hline cadres & 667 & 201 & 166 & 35 & 109 & 13 \\
\hline teachers & 866 & 310 & 252 & 17 & 15 & 5 \\
\hline
\end{tabular}

2) The implementation of interaction policy of teachers in urban and rural areas is damaged

Surface execution. In the process of policy implementation, some educational administrative departments and schools merely carry out the activities on the surface, and they walk through the motions to accomplish the task from higher level. The policies are not really put into implementation.

Alternative execution. They do everything by rule on the surface, but actually have a dark way to deal with something. ${ }^{6}$ For example, the quality school in the city will choose these teachers who meet the requirements but not excellent to go out and interact with each other. This will cause a great impact on the implementation quality of the interactive teachers in urban and rural areas.

\footnotetext{
${ }^{6}$ Zhu Min, Wu Xingang. Reflection on the Policy Distortion Phenomenon of Teacher's Rotation System [J]. Teaching and Administration, 2011, (22):1315
} 
Unilateral execution. In the process of policy implementation, the educational administration departments and schools unilaterally choose to carry out part of content, which may lead to a decline in the interactive enthusiasm and further hinder the smooth implementation of policy.

Utilitarian execution. The implementation of urban and rural teachers' interaction essentially is to balance urban and rural resources and improve the teachers' level. However, it involves the interests of all parties and has linked with promotion and so on, which make the interaction policy of urban and rural teachers change its flavor. Even some people want to gain opportunities for promotion by bribery and other means, resulting in corruption in education.

\section{3) The interaction quality of teachers in urban and rural} areas is uneven

Because the previous policy formulation is not sound and the policy implementation is damaged, it will inevitably lead to the poor implementation results. At present, Chengdu lacks unified inspection standards of teachers' interaction quality, and fails to investigate and evaluate the effectiveness scientifically, comprehensively and normatively. Even some data materials submitted on effectiveness are forged, and make other activities as urban and rural teachers' interactive activities, in attempt to confuse the concept and slip by. Because of the larger scope of interaction activity of urban and rural teachers, we cannot follow the investigation, which leads to the uneven interaction quality, and it is difficult to summarize the effectiveness and improve the next work accurately.

\section{Analysis of Causes of Poor Interaction between Urban and Rural Teachers in Chengdu}

If we want to analyze the reasons why the interaction between urban and rural teachers in Chengdu is hindered, we can summarize them by simple game. Assuming that the subjects of interaction between urban and rural teachers in Chengdu, namely the government, school, teacher and parents, are rational economic persons, we can analyze their respective interests and make different strategies. ${ }^{\top}$ Because students prefer to obey the parents' arrangement at the compulsory education stage, we eliminate the game analysis on students in this article.

\section{1) The government's interest demands and strategies}

The government's interest demands are as follows: first, government works hard to realize the balanced development of education. Second, government truly realizes the goal of balanced development of education. ${ }^{8}$ The former adopts the mandatory transition and pursues the effectiveness, which inevitably causes the conflict or formalism among all sides. The later needs to consume a lot of manpower, financial and material resources to solve the interests of all sides in the game, however, the cost is large and the effectiveness is slow. "Fig. 1 "

${ }^{7}$ K. J. Arrow. Social Choice: Many Individuals or Mary Criteria[M]. Qian Xiaomin and Meng Yueliang, Translate. Beijing: Capital University of Economics and Business Press, 2000: 47.

${ }^{8}$ Huang Qibing. Analysis of Teachers' Rotation System[J]. Journal of the Chinese Society of Education, 2012, (12):23-26

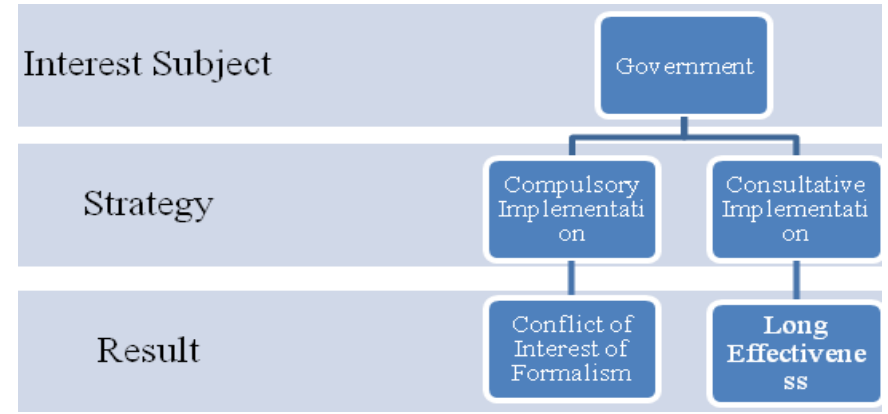

Fig. 1. Schematic Diagram of Government's Interest and Strategy.

\section{2) The school's interest demands and strategies}

The urban quality school's interest demands are to protect their school's vested interest from damage. The following strategic tendencies may exist: urban quality schools choose some poor teachers as excellent teachers to interact with other schools. Driven by this strategy, the original intention of interactive development between urban and rural teachers will be invalid. Government can apply random methods or other methods to select teachers to interact with other schools to avoid the occurrence of such a strategic tendency, but it will hit school's enthusiasm. ${ }^{9}$

However, for the poor schools in rural areas, the interaction between urban and rural teachers may bring great benefits: schools can receive better teacher's resource, and teachers can gain more opportunities for development, and the enrollment can get improved. Therefore, the poor schools in rural areas may be the biggest benefit gainer. However, the poor schools in rural areas may adopt the same strategy: they will choose some poor teachers as excellent teachers to interact with other schools, so as to retain the better resources of teachers. "Fig. 2 "'

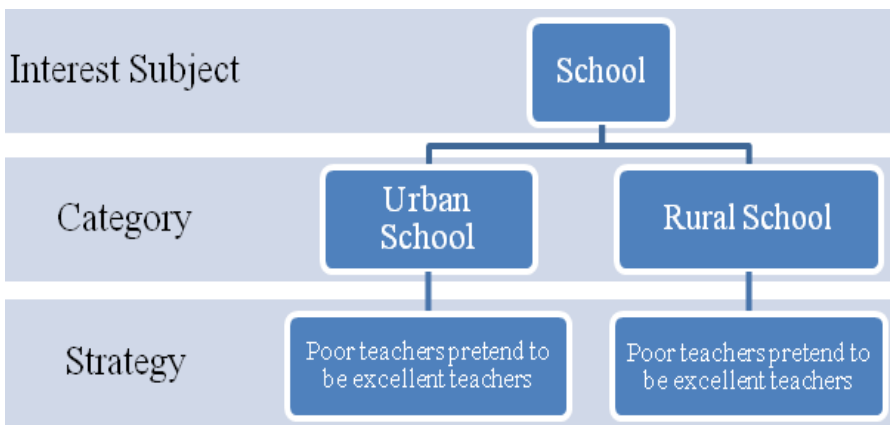

Fig. 2. Schematic Diagram of School's Interest and Strategy.

\section{3) The teachers' interest demands and strategies}

The teacher's interest demands of urban quality school are unwilling to or will choose good schools to interact with each other. They may resort to various measures to cope with this policy, such as malingering, divorce and pregnancy as an excuse to delay the interaction time. Or they will delay interaction time or choose more satisfied schools to interact by bribery or various power relations, which results in corruption

${ }^{9}$ Huang Qibing. Analysis of Teachers' Rotation System[J]. Journal of the Chinese Society of Education, 2012, (12):23-26 
in education. If there are no resources and means, teachers will go-slow. ${ }^{10}$

As for the teachers of rural poor school, they may transfer themselves to urban quality schools as soon as possible through bribery or power relations. No matter how long the policy will be implemented, they will be beneficiaries. "Fig. 3"

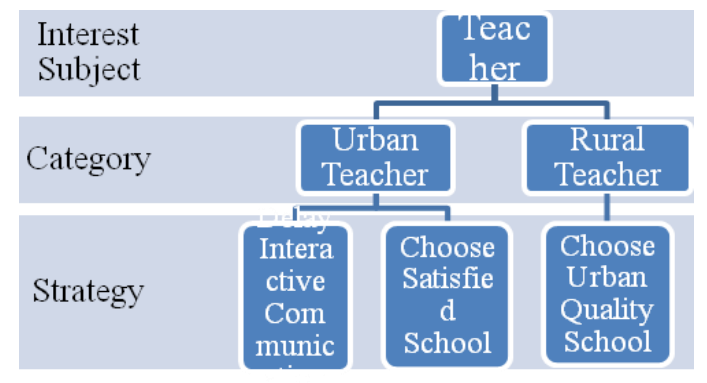

Fig. 3. Schematic Diagram of Teacher's Interest and Strategy.

\section{4) The parents' interest demands and strategies}

As for parents, it is their only interest demand to let their children enjoy quality education. Parents in the city have more resources and means than the rural parents to prevent children's teacher from interacting with other schools or to transfer their children to the class whose teachers do not interact with other schools. "Fig. 4"

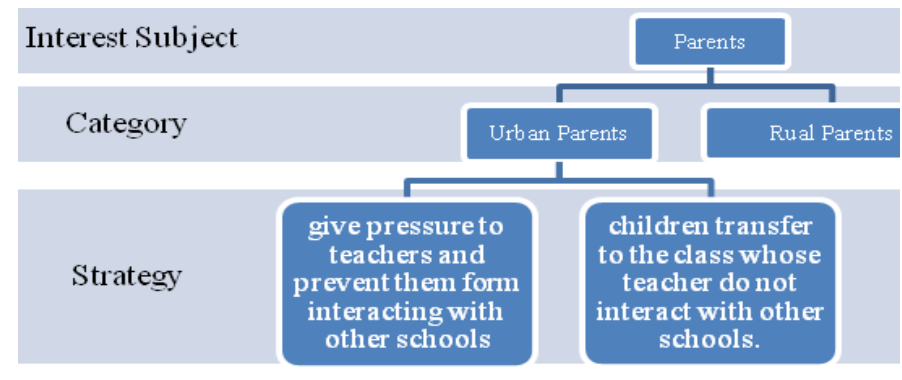

Fig. 4. Schematic Diagram of Parents' Interest and Strategy.

\section{COUNTERMEASURES AND SUGGESTIONS FOR} INNOVATING INTERACTIVE DEVELOPMENT OF URBAN AND RURAL TEACHERS IN CHENGDU

\section{A. Standardize the Interaction Process between Urban and Rural Teachers}

There are four links in formulating the standardized process of interactive development of urban and rural teachers: open selection, task setting, tracking supervision and evaluation of rewards and punishments, which includes the whole process of before-implementation of policy, policy implementation and after-implementation of policy. "Fig. 5"

\footnotetext{
${ }^{10}$ Huang Qibing. Analysis of Teachers' Rotation System[J]. Journal of the Chinese Society of Education, 2012, (12):23-26
}

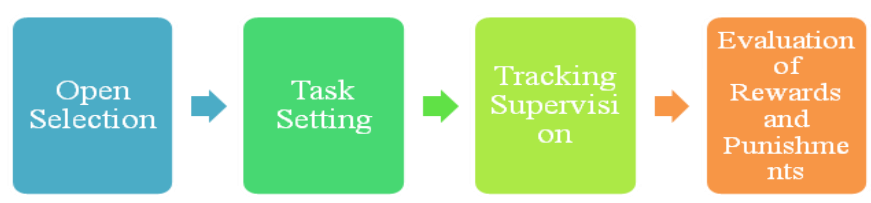

Fig. 5. Interaction Flow Chart of urban and rural teachers in Chengdu.

In the process of open selection, educational administrative department will deliver some requirements of the teacher's selection such as the number, age, rank, discipline, teaching time, communication time, communication post and other conditions $^{11}$ and policy intentions and policy significance to all schools, presenting to all teachers and avoiding the black box operation by administrative personnel.

These teachers who are selected will negotiate with the exchanged schools to formulate task, including teaching task, management task and other tasks, and the difficult degree of task should be moderate so as to avoid the go-slow which is brought by simple task and the fear of difficulty which is brought by difficult task. The task should be formulated in detail and will offer references to future supervision and assessment. $^{12}$

After the interactive activities officially start, we should organize the research analysts to constantly track the exchange conditions of teachers in school. Through interview and investigation on the spot and other ways to understand dynamic situation, on the one hand, we can give teachers humane care; on the other hand, we should urge and encourage teachers to redouble their efforts. In this link, it plays a role in the process of assessment at the same time.

After the interactive activity finishes, the interaction effects should be evaluated and assessed. We can formulate specific assessment indexes and give consideration to both qualitative and quantitative. The process assessment and final assessment are combined to evaluate the interactive teachers. We should give policy tilt to the teachers who have outstanding performance, such as appraising and rewards. And we can give criticism and education to those teachers who have poor performance, and if the circumstances are serious, they will be punished.

\section{B. Comprehensively Improve the Positivity of the Executive Subject}

The implementation of the policy is damaged mainly because of the improper consciousness of executive subject. Of course, it does not exclude the influences of objective factors.

To solve the problems of consciousness, we should strengthen the propaganda and mobilization of the policy, and publicize the positive effects of the interactive activities

${ }^{11}$ Chen Yuanhui. Study on the Solutions to the Problem of Binary Separation in Urban and Rural Areas - the Enlightenment of Japanese Teachers' Rotation System[J]. Teaching and Administration, 2009,(15): 156-157.

${ }_{12}$ Liu Wei, Zhu Chengke. The Plight and Countermeasures of the Implementation of Teacher's Rotation System in Rural Areas[J]. Teaching and Administration, 2010, (22):6-8. 
between urban and rural areas, and renew the education concept of urban and rural teachers by intensifying training. We also can set a typical example, and stimulate their own initiative of schools and teachers by the typical examples of exemplary role. We also should increase process feedback and praise those schools and teachers who have a good implementation of policy, and let them taste some "benefits".

In the questionnaire of teachers, we can find that although the executive subject has some deviations in consciousness, there are still objective factors to hinder it. $36.31 \%$ of teachers think that there are problems existing in the interactive communication of urban and rural teachers, for example, the distance is far away and the traffic is inconvenient. Due to family reasons, $16.51 \%$ is inconvenient to participate in communicative interaction in a long distance, for example, the old people are at home and children need to care. This requires investigating the family conditions of teachers in the process of selection and it would be best to allocate them nearby. If it is a long-term interactive communication, we should establish and improve the living facilities for teachers. "Fig. 6"

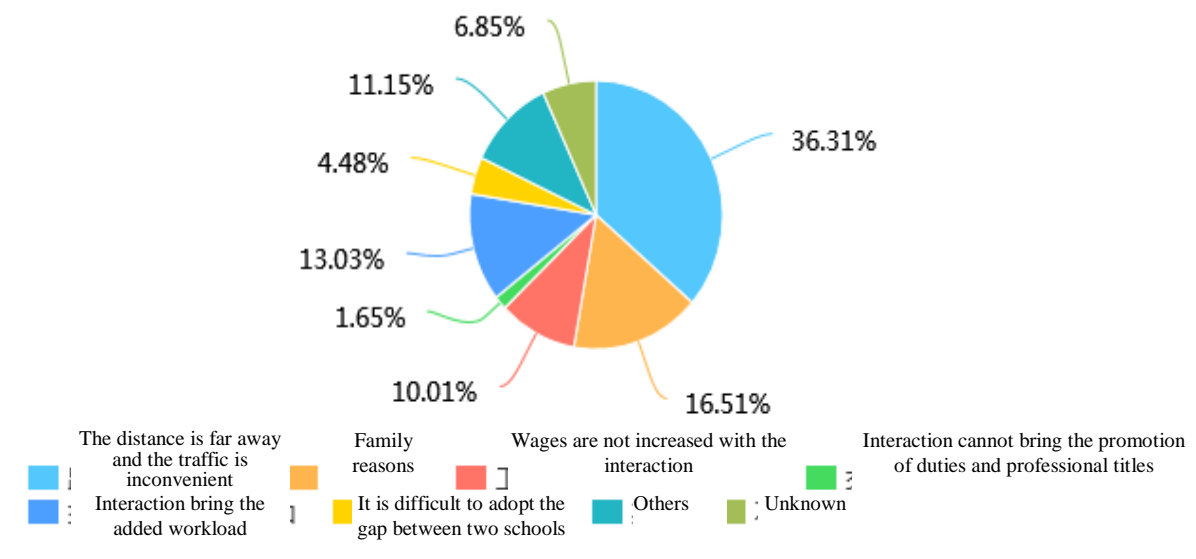

Fig. 6. Pie Chart of Factors of Hindering Teacher Interaction.

\section{The Interaction Results of Urban and Rural Teachers Are Strictly Evaluated}

In order to promote the interactive development between urban and rural teachers to gain substantial progress, it is necessary to explore and establish effect assessment index system of urban and rural teachers, and to strictly evaluate the interaction results. Aiming at the evaluation results, each subject can summarize the interactive effect and find out the deficiency in time, and put forward constructive suggestions for the future interactive development.

Generally speaking, the evaluation should experience three stages: initial stage (recognize reality and research problems), medium stage (tracking supervision and dynamic diagnosis) and final stage (summarize experience and foresee the future by reviewing the past). The evaluation subject may be the administrative departments of education bureau or expert team. But in the way of evaluation, all flowers bloom together, including investigation method (questionnaire, interview investigation), observation method, and literature research method and so on. However, the most important things in evaluation are to design evaluation contents before evaluating. Evaluation contents include the condition of school development, teacher development and student development and social satisfaction degree after interactive communication of urban and rural teachers. "Fig. 7"

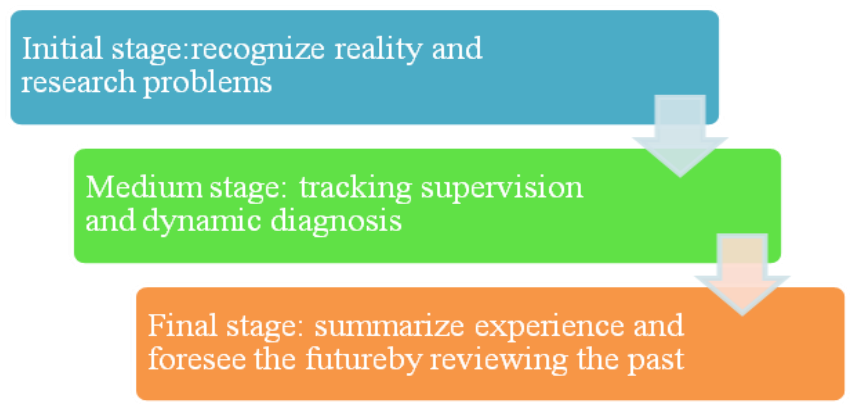

Fig. 7. Diagrammatic Sketch of Evaluation Stage.

\section{CONCLUSION}

At present, under the dualistic structure of urban and rural economy, there is a gap between urban and rural development, which is an inevitably problem in social development. Balancing urban and rural development has become one of the significant and strategic targets when our country enters into the 21 st century. Under this background, realizing the balanced development of urban and rural education has become an important measure and one of the core objectives of balancing urban and rural development. In 2007, Chengdu was approved as the pilot area of national coordinated urban and rural comprehensive reform, and the main task of pilot area was the theme of "coordinating urban and rural education". The interactive development of urban and rural teachers is the theme of this problem, through many years of practice, we should try our best to improve the integration of urban and rural teachers' level and realize the 
equalization of urban and rural educational services. However, there are many problems in the process of practice and there are some defects of varying degree in interactive formulation, interactive implementation and interactive effects. Through analyzing those problems and applying education, management science, economics and other professional knowledge, we can put forward some targeted and scientific innovative measures and promote the interactive development of urban and rural teachers to carry out in an orderly manner, and we should positively implement those measures and achieve remarkable results. The improvement of interactive development of urban and rural teachers in Chengdu has played a leading and exemplary role in other areas, which has a significant meaning for the implementation of coordinating urban and rural educational development strategy at the national level.

\section{REFERENCES}

[1] Chengdu Regional Education Alliance Development Report Compilation Group. Report on the Development of Chengdu Regional Education League[M]. Beijing: People's Publishing House, 2015: 3-45.

[2] Chenghao, Guanlei. Understanding of Public Goods Theory[J]. Journal of Hebei University of Economics and Trade, 2002, (06): 1017.

[3] Fang Fuqian. The Modern West Public Selection and Its Three Schools[J]. Teaching and Research, 1997, (10): 29-34+63.

[4] Song Yanqing, Wang Xuanhua. Literature Review of Public Choice Theory[J]. Commercial Times, 2009, (35):14-16.

[5] Chen Shuquan. A Study of the Policy Approach on Equalization of Compulsory Education Public Services: Taking Shandong Province for Example[J]. Shandong Social Sciences, 2011, (05):170-173.

[6] Zhu Min, Wu Xingang. Reflection on the Policy Distortion Phenomenon of Teacher's Rotation System[J]. Teaching and Administration, 2011, (22):13-15.

[7] K. J. Arrow. Social Choice: Many Individuals or Mary Criteria[M]. Qian Xiaomin and Meng Yueliang, Translate. Beijing: Capital University of Economics and Business Press, 2000: 47.

[8] Huang Qibing. Analysis of Teachers' Rotation System[J]. Journal of the Chinese Society of Education, 2012, (12):23-26.

[9] Liu Wei, Zhu Chengke. The Plight and Countermeasures of the Implementation of Teacher's Rotation System in Rural Areas[J]. Teaching and Administration, 2010, (22):6-8.

[10] Dandan Wang. Research on the Integration of Urban and Rural Education Process study based on Analysis of Educational Financial Resources Allocation [J] meici-15, 2015.

[11] Dandan Wang. Research on the Integration of Urban and Rural Education Process study based on Analysis of Educational Financial Resources' Allocation [J] International Conference on Management, 2015

[12] L Ran,D Wei,J Tan. On the integration process complexity of the urban and rural education practice [J]. Advances in Education, 2012. 